\title{
Fermilab
}

Managed by Fermi Research Alliance, LLC for the U.S. Department of Energy Office of Science

\section{National Labs Update for Librarians}

\author{
Sandra L. Lee
}

Annual Conference of the American Library Association

24 June 2017 


\section{National Labs}

- Fermilab is one of the 17 national laboratories of the U.S. Department of Energy.

- Large output of scientific and technical information

- Reports

- Articles

- Conference proceedings

- OSTI.gov

- Sci Tech Connect and PAGES

Most of the Labs will email PDFs of articles and a few will lend books 


\section{DOE National Lab Libraries Moving to digital content}

- Many of the National Labs are gradually replacing print books with eBooks

- Purchasing digital backfiles of serials continues

- A few Labs have no reading room or Ref Desk 


\section{Lab Libraries rapidly Digitizing Scientific Publications}

- Labs are heavily engaged with OSTI to meet Public Access goals

- Most Labs are also digitizing older articles and reports

- Many of the Lab Library departments include Technical Publications unit and are building stronger STI programs.

- Good news for borrowing libraries 


\section{Lab Libraries and Public Access to Scientific Publications}

- Some National Labs have had their own programs for more than 20 years, mostly run by the Lab Libraries, of digitizing their reports and putting their authors' journal article preprints online. After the 2013 Office of Science and Technology Policy Memorandum, "Increasing Access to the Results of Federally Funded Scientific Research," the Department of Energy began mandating and managing these processes through the Office of Scientific and Technical Information (OSTI.) 


\section{Lab Libraries and Public Access to Scientific Publications}

- Since October 1, 2014, all new journal articles funded by the Department of Energy must be freely available to the public as published articles on the publishers website or as accepted manuscripts available in full-text through OSTI. There may be a wait of up to one year for the full-text to be available to the public 


\section{National Labs Successful Purchasing Consortium}

- Adding about one new publisher each year for past 5 years

- Especially useful for a small Lab like Fermilab 


\section{Most of the Lab Libraries promoting ORCID}

- Encouraging authors to sign up

- Author disambiguation of Labs' Scientific Publications helps everyone

\section{Fermilab}




\section{INSPIRE http://inspirehep.net/}

High Energy Physics and Astrophysics databases:

- Literature

- Names

- Institutions

- Conferences

- Jobs

- Experiments

- Journals

Collaboration of Fermilab, CERN, DESY, IHEP and SLAC

Indexes over a million articles 


\section{ORCID \& INSPIRE http://inspirehep.net/}

- Authors submitting papers to INSPIRE must have ORCID registration

- Over 12,000 authors in INSPIRE are ORCID registered 


\section{Fermilab's 50th Anniversary}

- Founded June 15, 1967

- Fermilab employs about 1,800 employees and hosts the second-largest particle accelerator laboratory in the world.

- Located in Batavia, Illinois 


\section{Questions?}

- sllee@fnal.gov 